Meta

Journal des traducteurs

Translators' Journal

\title{
L'image marquée par la culture : une réflexion sur des marqueurs culturels dans la bande dessinée
}

\section{Sabrina Moura Aragão}

Volume 60, numéro 2, août 2015

$60^{\mathrm{e}}$ anniversaire. Les horizons de la traduction : retour vers le futur $60^{\text {th }}$ Anniversary. Translation's Horizons: Back to the Future

60 mo aniversario. Los horizontes de la traducción: regreso al futuro

URI : https://id.erudit.org/iderudit/1032909ar

DOI : https://doi.org/10.7202/1032909ar

Aller au sommaire du numéro

Éditeur(s)

Les Presses de l’Université de Montréal

ISSN

0026-0452 (imprimé)

1492-1421 (numérique)

Découvrir la revue

Citer ce document

Moura Aragão, S. (2015). L'image marquée par la culture : une réflexion sur des marqueurs culturels dans la bande dessinée. Meta, 60(2), 358-358.

https://doi.org/10.7202/1032909ar d'utilisation que vous pouvez consulter en ligne. 


\title{
L'image marquée par la culture: une réflexion sur des marqueurs culturels dans la bande dessinée
}

\author{
Sabrina Moura Aragẽo \\ Universidade de São Paulo, São Paulo, Brésil \\ sabrina.aragao@usp.br
}

Le présent travail a pour objectif d'élargir le champ de recherche sur la question des marqueurs culturels, largement considérée par la traductologie. Afin de proposer cette réflexion, nous tenons compte de l'hypothèse selon laquelle les marqueurs culturels se présentent dans l'image et pas seulement dans le texte, surtout dans les formes expressives qui utilisent l'image pour transmettre un message, comme les bandes dessinées. Ainsi, nous examinerons la manière dont les marqueurs culturels se présentent dans les images et dans le texte de la série de bande dessinée française Le Photographe et dans sa traduction en portugais du Brésil (O fotógrafo).

Publiée en France en trois volumes entre 2003 et 2006, la série Le Photographe a été composée par Didier Lefèvre (photographe), Emmanuel Guibert (dessinateur) et Frédéric Lemercier (éditeur). La traduction brésilienne a paru en 2006. Cette bande dessinée est un exemple de mélange de codes visuels et de formes discursives, car on y observe le langage de la bande dessinée elle-même, ainsi que le langage journalistique, une fois qu'elle raconte le quotidien et montre le travail des médecins et infirmiers de l'organisation Médecins Sans Frontières pendant les conflits en Afghanistan dans les années 1980. Dans les bandes dessinées en général, l'élément iconique a une fonction énonciative, c'est-à-dire qu'il transmet un message à partir d'un contexte qui peut, ou non, être associé à un texte.

Le Photographe met en contact la culture française avec la culture afghane, tandis que $O$ fotógrafo refait le portrait de la culture afghane pour les Brésiliens à partir d'une vision française. Il y a une relation entre l'usage des marqueurs culturels et la formation d'identités et d'opinions sur un peuple étranger. Ainsi, les images et la sélection lexicale dans les textes des bandes dessinées contribuent à la propagation de points de vue qui, en contexte de traduction, révèlent de nouvelles questions et possibilités de réflexion. À travers des choix d'angle (dans la photographie) et des choix discursifs (dans le texte), des photographes, des écrivains et des traducteurs laissent des traces de leurs propres visions qui, à la fois, sont interprétées, acceptées, niées, bref, constamment transformées, par le public.

Étudiante au doctorat à l'Universidade de São Paulo (USP), ses travaux de recherche portent sur l'image dans le processus de traduction, notamment dans les bandes dessinées. En 2012, elle a obtenu le Master en lettres avec le mémoire Imagem e texto em tradução: uma análise do processo tradutório nas histórias em quadrinhos. Elle a publié les articles suivants en 2014: «O corpo fala, mas em que língua ?: o gesto e a fala na tradução de quadrinhos » dans la revue Artefactum et «lls sont fous ces traducteurs: considerações sobre a tradução do humor em Astérix» dans In-Traduções. Elle est aussi coauteure avec Adriana Zavaglia de Histórias em quadrinhos imagem e texto em tradução publié dans Tradterm en 2010. 